\title{
Active Learning for Business Communication Competencies: Modifying Teaching Practices and Pedagogies in Higher Education
}

\section{Terrill Reid McLain}

Hankuk University of Foreign Studies, Yongin, Korea

Are business schools adequately preparing graduates to be ready for the interactions that they will face in the professional world? Some studies and research have found that they are not prepared for these interactions and that graduates lack these communication skills (Stevens, 2005). A recent study of the top business schools in Korea measured the existence of business communication programs in higher education. It concluded that more courses in business communication as a required element are needed (Chang, Park, \& Cho, 2018). This study also discussed the need for curriculum development to focus on the consumer, i.e., the students and the industry at large (Chang et al., 2018, p. 38).

For instructors who teach business classes in higher education, this becomes a challenge if the state quo class style is based on the lecture and exam model of learning. However, there are other methods of instruction that can be easily used instead of or as a supplement to current course designs. These alternative methods have ample research to support the use in the classroom. Using this research as evidence, it can serve as an advocate for instructors to modify their pedagogies to include these

Received: Jun 3, 2019 Revised: Jun 25, 2019 Accepted: Jun 28, 2019 Corresponding author: Terrill Reid McLain

Hankuk University of Foreign Studies, 81 Oedae Ro, Mohyeon-myeon, Cheoin-gu, Yongin-si, Gyeonggi-do, 17035, Korea

Tel: +82-31-330-4114, E-mail: reidmclain@hufs.ac.kr

This is an Open Access article distributed under the terms of the Creative Commons Attribution Non-Commercial License (http://creativecommons.org/licenses/ by-nc/4.0/) which permits unrestricted non-commercial use, distribution, and reproduction in any medium, provided the original work is properly cited.

Copyright $(9) 2019$ Korean Association for Business Communication. engaging and alternative tasks and assignments in their classes. This pedagogical modification towards active learning may also benefit students by helping boost their communication competency assessments at the end of a semester.

When active learning activities are used in combination with reflective learning, classes become even more useful for learners. These techniques for interaction and reflections, not only assist in aiding learners with higher scores but are a safe way to practice communicating professionally by using critical and reflective thinking while still in school and receiving feedback on it, i.e., before it can negatively affect a company's bottom line. This paper will establish the need for a research and learner-based approach to higher education course building, define reflective and active learning, and outline the technique called Jigsaw as one technique to illustrate ways to implement these alternative and research-based classroom approaches.

\section{Research Based Approach}

Instructional designers Miriam Larson and Barbara Lockee believe that "lifelong learning is crucial to the survival of individuals and societies, and therefore there is an ongoing, critical need for effective learning experiences and environments" (Larson \& Lockee, 2013, p. 2). While researchers are still looking at how humans learn, there are current studies that have strong evidence to effectively shape curriculum and make productive learning environments for students that may also help with improving learner outcomes. These alternative methods are being embraced and implemented by educators at many levels; however, many 
classes in higher education still use the lecture and listen model for courses.

There is some evidence that may indicate that the lecture-based approach to learning may produce inferior assessment results regarding communication skills (see Garner \& Chan, 2019; Wijnia, Loyens, \& Derous, 2011). There is a disconnect with these changes in higher education; between the research and what is-or can more effectively be-done in the classroom. Higher Education Quarterly talks about this disconnect and advocates for a research-based curricula (Elsen, VisserWijnveen, van der Rijst, \& van Driel, 2009).

Using existing cognitive and learning research makes it easier to justify the change in class style, and for some, may help persuade colleagues to understand the need for the changes. In one example, a 2019 Study on the Flipped Classroom versus the traditional lecture-based class, found that the more active learning implementation of a flipped classroom was more effective at improved communication competency assessments at the end of the semester compared to a lecture of the same material (Garner \& Chan, 2019). Using this research and others like it, instructors can confidently modify their classes to be active and help improve student motivation and assessment outcomes for the coursework.

\section{Student Centered Learning}

Instructional designers advocate that when students are engaged actively (rather than passively) with the course material that learning takes place (see Davidson-Shivers, Rasmussen, \&
Lowenthal, 2018). Students have an easier time remembering the material when they are engaged. Activities that include an interaction between students and others are engaging activities as the communication takes place naturally. As cited in a 2017 study on problem-based learning versus lecture-based learning and the effect on student motivation, students who are motivated spend more time with the material than those who are not (Wijnia et al., 2011).

Communication is also a competency that can be practiced in simulations, games, presentations, discussions, and writing. To prepare to communicate at a professional level, students can be producing the language and self-evaluate their learning and interactions regularly - in class - to help them improve both ability and confidence for future scenarios. Making this shift to focus on learners, the instructor becomes a facilitator.

In some cases, the instructor becomes the lead-learner and the job of the instructor is transformed to help guide the learning and learn alongside students. As the students become the focus of the lesson objectives, they begin to actively participate in their learning and rather than passively receiving ideas. Cognitive researchers have identified taxonomies that help shift the focus on learners by using verbs to identify class goals. One example is Bloom's Taxonomy and in its current iteration, Bloom's Revised Taxonomy (Anderson, Krathwohl, \& Bloom, 2001). These taxonomies are a hierarchical framework for classifying educational goals and can be seen in Figure 1.

Blooms Revised Taxonomy is focused on the verbs, and "these 'action words' describe the cognitive processes by which think-

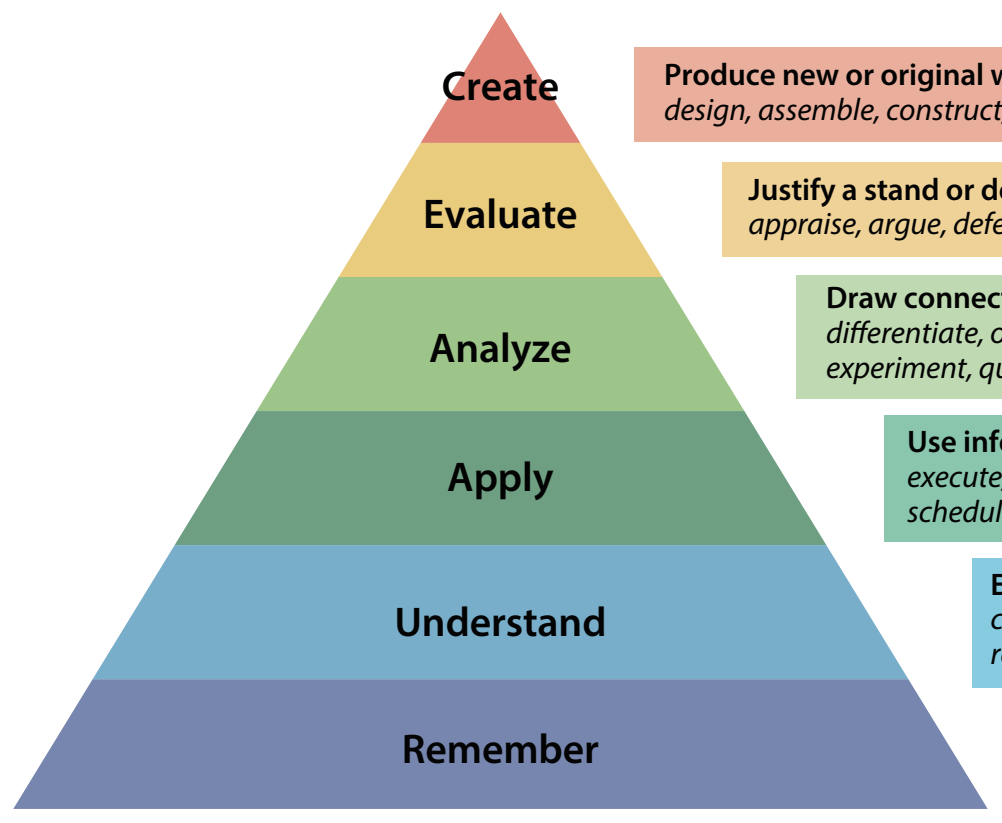

classify, describe, discuss, explain, identify, locate, recognize,
report, select, translate
Recall facts and basic concepts
define, duplicate, list, memorize, repeat, state

Figure 1. Bloom's Taxonomy Graphic. Adapted from “Bloom's Taxonomy" by Armstrong, 2018. CC BY. 
ers encounter and work with knowledge" (Armstrong, 2018). Using instructor-centered only approaches to class objectives makes it harder to reach the higher levels of the taxonomy since the learner is required to do the actions. Therefore, to complete the upper levels of the taxonomy and implement them in class for learners, the objectives need to include elements of reflective and active learning.

\section{Reflective Learning}

Reflective learning, and as an extension, critical thinking are the results of a cognitive process; this process can include a written or oral type of activity where learners can show their thinking. Research shows the importance of such events in business education (see Baker, 1996; Desai, Berger, \& Higgs, 2016; Tugui, 2013). Reflective learning gives a learner the chance to think, but also to take one step more and be able to express what they have learned and seek to apply the learning to future contexts. Courses can be designed to help students with complicated thinking about their work and help them with decisions with uncertain future situations (Boud \& Falchikov, 2006).

Reflective learning is also a cognitive practice for solo learners to rearrange the concepts that they have learned into words and share with others; this is communication in action. To measure these types of activities, it is essential to choose learning objectives that move the learner to reflect on their interactions. To assist with this, instructors can use a rubric based on Queensland University of Technology's (QUT) writing program and The Four R's of Reflection (Ryan \& Ryan, 2010). The Four R's are defined as: reporting, tell what happened; relating, making connections to existing knowledge; reasoning, showing the understanding of what was learned; and reconstructing, discussing how the learning can be applied in the future. As reflective learning is key for individuals, it is necessary to place learners in situations where they can activate reflections.

\section{Active Learning}

Active learning activities, when applied in the classroom, can lend themselves to communication competency practice and interactions by providing an engaging classroom and stronger learning. Some studies have shown that these interactions have helped learners understand the material better, even if the discussion and project interaction was uncomfortable for learners at first (Cavanagh, 2011). This same study showed that the students felt more engaged and present in the lessons. As noted by Cavanagh, the "diversity of activities helped them stay focused because the activities 'broke up the time' and 'kept me alert and thinking' by 'involving us'"(Cavanagh, 2011, p. 28). Active learning provides situations for learners to use their reflection and critical thinking skills, and the activities can be designed to access the higher levels on Bloom's Taxonomy.

There are various kinds of Active Learning techniques that can be applied in the classroom so that students are engaged. Discussions, case studies, role-plays, simulations, problem and project-based learning, presentations, and service learning are all ways that instructors can modify the classroom to be more active and provide opportunities for learners to engage. A technique called Jigsaw is a subtype of these activities and can use a combination of the above. This technique has been used in various class subjects from the medical field to communication competencies. The finding from this research shows to some relative success and improved outcomes from using the Jigsaw Method (see Sagsoz, Karatas, Turel, Yildiz, \& Kaya, 2017; Wilson, Pegram, Battise, \& Robinson, 2017; Yoshida, 2018).

\section{Jigsaw Activities}

Jigsaw activities are a cooperative learning technique that has the students teaching the material to each other. This engagement and student driven activity compels the students to explore and find the material with the added accountability of peer learning. The instructor becomes a facilitator guiding student and only intervenes when there are problems to solve.

Here is a brief outline of how a Jigsaw works:

1. Students divide into learning groups.

- To start, divide the class into smaller Home Groups. If the class is small, it can serve as the Home Group

- Adjust the size of the Home Group to meet the needs of the class enrollment. The number in a team depends on how many topics/concepts are to be taught

2. Students then break out into different Subject Matter Expert groups

- The number of students sent from the Home Groups to be Subject Matter Experts also depends on the enrollment - Large classes may choose to send students in pairs

- Small classes may choose to send individual group members

\section{Subject Matter Expert Groups}

- Research a topic together in their Subject Matter Expert Groups and become experts in the subject or competency being studied

4. The subject matter experts return to their Home Groups and "teach" their team about their subject

- Part 1 [Presentation]: Subject Matter Expert presents 
their material to their Home Groups

- Part 2 [Dialogue]: Home Groups then ask questions to the Subject Matter Expert and a discussion takes place to solidify the understanding of the topic

5. Finish the activity and allow for student reflection

Jigsaws may be "rapid" which takes place only in class as a scavenger hunt with a time limit or may take place as homework over a longer period.

\section{Conclusion}

For higher education business schools and classes to adequately prepare students for the workplace with strong communication competencies and critical thinking; instructors should modify class objectives to include a student-centered approach based on solid research. These objectives should consist of activities that promote reflective learning. Techniques such as the Jigsaw Technique are one of many that can be used to engage learners in a class. The implementation of active learning in the classroom may improve students' satisfaction with the courses, and ultimately their assessment scores at the end of a semester.

\section{References}

Anderson, L. W., Krathwohl, D. R., \& Bloom, B. S. (2001). A taxonomy for learning, teaching, and assessing: A revision of Bloom's taxonomy of educational objectives. New York, NY: Longman.

Armstrong, P. (2018). Bloom's taxonomy. Retrieved from https:// cft.vanderbilt.edu/guides-sub-pages/blooms-taxonomy

Baker, C. R. (1996). Reflective learning: A teaching strategy for critical thinking. Journal of Nursing Education, 35(1), 19-22.

Boud, D., \& Falchikov, N. (2006). Aligning assessment with longterm learning. Assessment \& Evaluation in Higher Education, 31(4), 399-413.

Cavanagh, M. (2011). Students' experiences of active engagement through cooperative learning activities in lectures. Active Learning in Higher Education, 12(1), 23-33.

Chang, H., Park, P., \& Cho, S. (2018). An analysis of business communication courses in business schools and suggestions for curriculum development. Business Communication Research and
Practice, 1(1), 33-40.

Davidson-Shivers, G. V., Rasmussen, K. L., \& Lowenthal, P. R. (2018). Foundations of online learning and instructional design. In Web-based learning (pp. 43-79). Cham, Switzerland: Springer.

Desai, M. S., Berger, B. D., \& Higgs, R. (2016). Critical thinking skills for business school graduates as demanded by employers: A strategic perspective and recommendations. Academy of Educational Leadership Journal, 20(1), 10-31.

Elsen, M. G. M. F., Visser-Wijnveen, G. J., van der Rijst, R. M., \& van Driel, J. H. (2009). How to strengthen the connection between research and teaching in undergraduate university education. Higher Education Quarterly, 63(1), 64-85.

Garner, B., \& Chan, M. (2019). Student perceptions of learning and engagement in a flipped versus lecture course. Business and Professional Communication Quarterly, 82(3), 357-369.

Larson, M. B., \& Lockee, B. B. (2013). Mastering the basics. In Streamlined ID: A practical guide to instructional design (pp. 1-19). New York, NY: Routledge.

Ryan, M., \& Ryan, M. (2010). The 4Rs model of reflective thinking. Retrieved from https://www.citewrite.qut.edu.au/write/ reflectivewriting.jsp

Sagsoz, O., Karatas, O., Turel, V., Yildiz, M., \& Kaya, E. (2017). Effectiveness of Jigsaw learning compared to lecture-based learning in dental education. European Journal of Dental Education, 21(1), 28-32.

Stevens, B. (2005). What communication skills do employers want? Silicon Valley recruiters respond. Journal of Employment Counseling, 42(1), 2-9.

Tugui, C. (2013). Can we innovate teacher education using business reflective learning methods? Procedia - Social and Behavioral Sciences, $83,717-722$.

Wijnia, L., Loyens, S. M. M., \& Derous, E. (2011). Investigating effects of problem-based versus lecture-based learning environments on student motivation. Contemporary Educational Psychology, 36(2), 101-113.

Wilson, J. A., Pegram, A. H., Battise, D. M., \& Robinson, A. M. (2017). Traditional lecture versus jigsaw learning method for teaching Medication Therapy Management (MTM) core elements. Currents in Pharmacy Teaching and Learning, 9(6), 1151-1159.

Yoshida, M. (2018). Communication Jigsaw: A teaching method that promotes scholarly communication. International Journal of Emerging Technologies in Learning, 13(10), 208-224. 